\title{
Comparative epidemiology of sudden infant death syndrome and sudden intrauterine unexplained death
}

\author{
J F Frøen, M Arnestad, Å Vege, L M Irgens, T O Rognum, O D Saugstad, B Stray-Pedersen
}

Arch Dis Child Fetal Neonatal Ed 2002;87:F1 18-F122

See end of article for authors' affiliations ......................

Correspondence to: Dr Frøen, Department of Pediatric Research, The National Hospital,

University of Oslo, N-0027

Oslo, Norway;

i.f.froen@klinmed.vio.no

Accepted

14 February 2002

\begin{abstract}
Background: Unexplained antepartum stillbirth and sudden infant death syndrome (SIDS) are major contributors to perinatal and infant mortality in the western world. A relation between them has been suggested. As an equivalent of SIDS, only cases validated by post mortem examination are diagnosed as sudden intrauterine unexplained death (SIUD).

Objective: To test the hypothesis that SIDS and SIUD have common risk factors.

Methods: Registration comprised all stillbirths in Oslo and all infant deaths in Oslo and the neighbouring county, Akershus, Norway during 1986-1995. Seventy six cases of SIUD and 78 of SIDS were found, a long with 582 random controls surviving infancy, all singletons. Odds ratios were obtained by multiple logistic regression analysis.

Results: Whereas SIUD was associated with high maternal age, overweight/obesity, smoking, and low education, SIDS was associated with low maternal age, smoking, male sex, multiparity, proteinuria during pregnancy, and fundal height exceeding +2 SD. Thus the effects of maternal age were opposite in SIUD and SIDS (adjusted odds ratio 1.39 (95\% confidence interval 1.17 to 1.66 ) per year, $\mathrm{p}<0.0005)$. Heavy smoking, male sex, and a multiparous mother was less likely in SIUD than in SIDS $(0.22(0.06$ to 0.83$), 0.22(0.07$ to 0.78$)$, and $0.03 \quad(<0.01$ to 0.17$)$ respectively). Overweight/obesity and low fundal height were more common in SIUD than in SIDS (7.45 (1.49 to 37.3 ) and 13.8 (1.56 to 122 ) respectively).

Conclusions: The differences in risk factors do not support the hypothesis that SIDS and SIUD have similar determinants in maternal or fetal characteristics detectable by basic antenatal care.
\end{abstract}

\section{MATERIALS AND METHODS}

The registration period was 1986-1995. Details on the collection and identification of valid cases of singleton SIUD in Oslo, Norway, have been published previously. ${ }^{3}$ In brief, data were collected both through the Medical Birth Registry of Norway (MBRN) which is based on compulsory notification of all births with a gestational age of 16 weeks or more, ${ }^{5}$ and through the ICD 9 diagnosis registries of all hospitals in the region. A total of 589 reported stillbirths was identified. Two of these could not be found in the hospital archives and three were not citizens of Oslo, and were excluded. Seventy six cases were validated as singleton SIUD. In addition, 582 singleton liveborn infants who had survived their first year of life were randomly selected as controls and identified through the MBRN.

SIDS cases in Oslo and the neighbouring county, Akershus, were identified by validating all cases of infant deaths occurring between 2 and 52 weeks of age registered through the MBRN, the cause of death registry of the Central Bureau of Statistics of Norway (also based on compulsory notification), and the registries of all departments of pathology and forensic medicine in the region. Seventy eight cases were ascertained as singleton SIDS.

The data collected from MBRN included basic information on the mother and fetus, and data on pregnancy, labour, and delivery. Medical records with data on the fetus and mother at admission and during labour and delivery, mother's obstetric history, midwives notification forms, and results of the medical examinations following stillbirth or infant death were found for all cases. Most (98\%) of the standardised records of antepartum care (mother's health card) kept by doctors and

Abbreviations: SIDS, sudden infant death syndrome; SIUD, sudden intrauterine unexplained death; IUGR, intrauterine growth restriction
SIUD in terms of maternal and fetal characteristics that are detectable through basic antenatal care. 


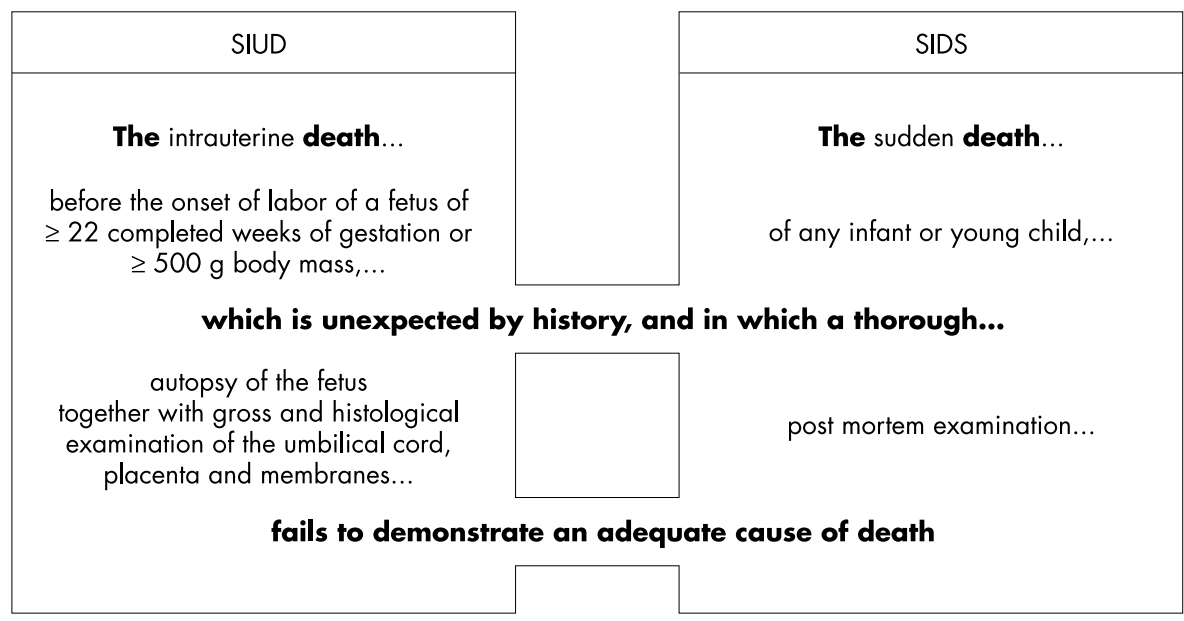

Figure 1 Definitions of sudden infant death syndrome (SIDS) and sudden intrauterine unexplained death (SIUD).

midwives were found; they contained mother's obstetric history, medical history, smoking habits (recorded at the first antenatal visit), health during pregnancy, antepartum visits, height, weight gain during pregnancy, measurements of fundal height, results of ultrasound screening, and other tests performed during pregnancy.

Intrauterine growth restriction (IUGR) estimation was based on customised weight centiles for fetal growth corrected for gestational age, ethnicity, maternal height, weight, age, and parity, as described for SIUD. Low fundal height was defined as more than 2 SD below the mean, or a decrease in fundal height of $1 \mathrm{~cm}$ (despite fundal height being within \pm 2 SD) between two consecutive antenatal visits, and high fundal height was defined as more than 2 SD above the mean. Only registrations during the second or third trimester were used, and the standard population based growth curves in the maternity cards were used.

All statistics were performed with SPSS 10.0.7. Cross tables with $\chi^{2}$ tests and logistic regression with one covariate were used to find crude (unadjusted) odds ratios (OR) with 95\% confidence intervals (CI), and to decide whether observed differences were significant. Cross tables were also used to detect possible associations between covariates. Multiple logistic regression was used to obtain adjusted OR to test for possible interaction terms. The Hosmer-Lemeshow test was used to test goodness of fit of the different models. Pearson's two tailed test was used to detect correlations.

Table 1 Cases of sudden infant death syndrome (SIDS), sudden intrauterine unexplained death (SIUD), and surviving controls by basic and clinical variables

\begin{tabular}{|c|c|c|c|c|c|c|}
\hline \multirow[b]{2}{*}{ Variable } & \multicolumn{2}{|l|}{ SIDS } & \multicolumn{2}{|l|}{ SIUD } & \multicolumn{2}{|l|}{ Controls } \\
\hline & Number & Valid \% & Number & Valid \% & Number & Valid $\%$ \\
\hline \multicolumn{7}{|l|}{ Age at last menstruation } \\
\hline$<25$ years & 32 & 42.7 & 18 & 23.6 & 154 & 26.5 \\
\hline $25-29$ & 25 & 33.3 & 28 & 36.8 & 215 & 36.9 \\
\hline $30-35$ & 13 & 17.3 & 22 & 28.9 & 154 & 26.5 \\
\hline$>35$ years & 5 & 6.7 & 8 & 10.5 & 59 & 10.1 \\
\hline \multicolumn{7}{|l|}{ Maternal smoking } \\
\hline No & 27 & 41.5 & 43 & 62.3 & 396 & 74.9 \\
\hline 1-9 cigarettes/day & 11 & 16.9 & 10 & 13.2 & 92 & 17.4 \\
\hline$\geqslant 10$ cigarettes/day & 27 & 41.5 & 16 & 21.1 & 41 & 7.8 \\
\hline \multicolumn{7}{|l|}{ Maternal parity } \\
\hline 0 births & 20 & 28.2 & 37 & 52.1 & 308 & 53.8 \\
\hline 1 birth & 29 & 40.8 & 24 & 33.8 & 176 & 30.8 \\
\hline 2 births & 15 & 21.1 & 3 & 4.2 & 58 & 10.1 \\
\hline 3 births & 6 & 8.5 & 4 & 5.6 & 18 & 3.1 \\
\hline $4+$ births & 1 & 1.4 & 3 & 4.2 & 12 & 2.0 \\
\hline Previous stillbirths or abortions & 10 & 14.3 & 10 & 14.1 & 94 & 16.4 \\
\hline Previous induced abortions & 19 & 26.8 & 15 & 20.8 & 135 & 23.5 \\
\hline Body mass index $>25 \mathrm{~kg} / \mathrm{m}^{2}$ & 8 & 13.1 & 17 & 27.0 & 56 & 11.7 \\
\hline Ethnic origin Europe (EU) & 71 & 97.2 & 62 & 85.0 & 468 & 85.1 \\
\hline \multicolumn{7}{|l|}{ Education } \\
\hline$<10$ years & 18 & 32.1 & 16 & 28.6 & 69 & 15.9 \\
\hline $10-12$ & 23 & 41.1 & 21 & 37.5 & 151 & 34.9 \\
\hline$>12$ years & 15 & 26.8 & 19 & 33.9 & 213 & 49.2 \\
\hline Glucosuria & 9 & 14.1 & 13 & 18.8 & 97 & 16.8 \\
\hline Proteinuria & 16 & 24.2 & 12 & 17.4 & 66 & 11.5 \\
\hline Abnormally high fundal height & 28 & 45.9 & 27 & 41.5 & 188 & 34.2 \\
\hline Abnormally low fundal height & 5 & 8.2 & 8 & 12.3 & 30 & 5.5 \\
\hline Male & 52 & 66.7 & 40 & 54.8 & 296 & 50.9 \\
\hline Death autumn/winter* & 53 & 69.7 & 41 & 53.9 & 281 & 48.3 \\
\hline Preterm birth (<38 weeks) & 10 & 13.3 & 37 & 48.7 & 35 & 6.0 \\
\hline Unrelated parents & 78 & 100.0 & 68 & 94.4 & 558 & 96.9 \\
\hline
\end{tabular}


Table 2 Adjusted odds ratios for sudden infant death syndrome (SIDS) compared with sudden intrauterine unexplained death

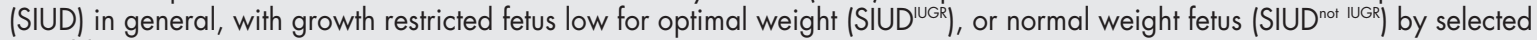
variables

\begin{tabular}{|c|c|c|c|c|c|}
\hline Variable & $\begin{array}{l}\text { SIUD } v \text { controls } \\
\text { OR adi }(95 \% \mathrm{CI})\end{array}$ & $\begin{array}{l}\text { SIDS } v \text { controls } \\
\text { OR adj }(95 \% \mathrm{CI})\end{array}$ & $\begin{array}{l}\text { SIUD } v \text { SIDS } \\
\text { OR adj }(95 \% \mathrm{CI})\end{array}$ & $\begin{array}{l}\text { SIUDDUGR } v \text { SIDS } \\
\text { OR adi }(95 \% \mathrm{CI})\end{array}$ & $\begin{array}{l}\text { SIUD not IUGR } v \text { SIDS } \\
\text { OR adj }(95 \% \text { CI) }\end{array}$ \\
\hline \multicolumn{6}{|l|}{ Body mass index } \\
\hline$<25 \mathrm{~kg} / \mathrm{m}^{2}$ & Ref & Ref & Ref & Ref & Ref \\
\hline$\geqslant 25 \mathrm{~kg} / \mathrm{m}^{2}$ & 3.14 (1.24 to 7.97$)$ & Excluded as NS & 7.45 (1.49 to 37.3$)$ & Excluded as NS & $21.7(2.25$ to 208$)$ \\
\hline \multicolumn{6}{|l|}{ Smoking } \\
\hline No smoking & Ref & Ref & Ref & Ref & Ref \\
\hline$<10 \mathrm{cig} /$ day & NS & $1.93(0.83$ to 4.50$)$ & NS & Excluded as NS & $0.04(<0.01$ to 1.07$)$ \\
\hline$\geqslant 10 \mathrm{cig} /$ day & 3.04 (1.13 to 8.19$)$ & 8.96 (3.94 to 20.4 ) & $0.22(0.06$ to 0.83$)$ & & $0.12(0.02$ to 0.84$)$ \\
\hline \multicolumn{6}{|c|}{ Age (linear regression) } \\
\hline Risk/year & $1.11(1.04$ to 1.20$)$ & 0.85 (0.78 to 0.92$)$ & 1.39 (1.17 to 1.66$)$ & 1.37 (1.17 to 1.62$)$ & 1.49 (1.15 to 1.92$)$ \\
\hline \multicolumn{6}{|l|}{ Proteinuria } \\
\hline No & Ref & Ref & Ref & Ref & Ref \\
\hline Yes & Excluded as NS & $3.51(1.56$ to 7.88$)$ & Excluded as NS & $0.14(0.02$ to 0.89$)$ & Excluded as NS \\
\hline \multicolumn{6}{|c|}{ Fundal height abnormality } \\
\hline No & Ref & Ref & Ref & Ref & Ref \\
\hline Low & Excluded as NS & NS & $13.8(1.56$ to 122$)$ & 7.82 (1.42 to 43.2 ) & Excluded as NS \\
\hline High & & 2.05 (1.03 to 4.09 ) & NS & NS & \\
\hline \multicolumn{6}{|l|}{ Primiparity } \\
\hline Yes & Ref & Ref & Ref & Ref & Ref \\
\hline No & Excluded as NS & 8.78 (3.84 to 20.1$)$ & $0.03(<0.01$ to 0.17$)$ & $0.04(0.01$ to 0.21$)$ & $<0.01 \quad(<0.01$ to 0.16$)$ \\
\hline \multicolumn{6}{|r|}{ 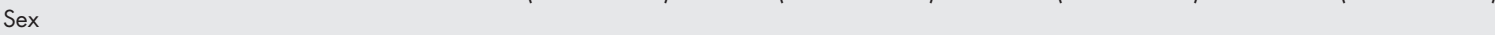 } \\
\hline Female & Ref & Ref & Ref & Ref & Ref \\
\hline Male & Excluded as NS & $2.17(1.10$ to 4.28$)$ & $0.22(0.07-0.78)$ & $0.24(0.07$ to 0.84$)$ & $0.13(0.02$ to 0.82$)$ \\
\hline \multicolumn{6}{|l|}{ Education } \\
\hline$<10$ years & 2.89 (1.25 to 6.68$)$ & Excluded as NS & Excluded as NS & Excluded as NS & Excluded as NS \\
\hline 10 years + & Ref & Ref & Ref & Ref & Ref \\
\hline
\end{tabular}

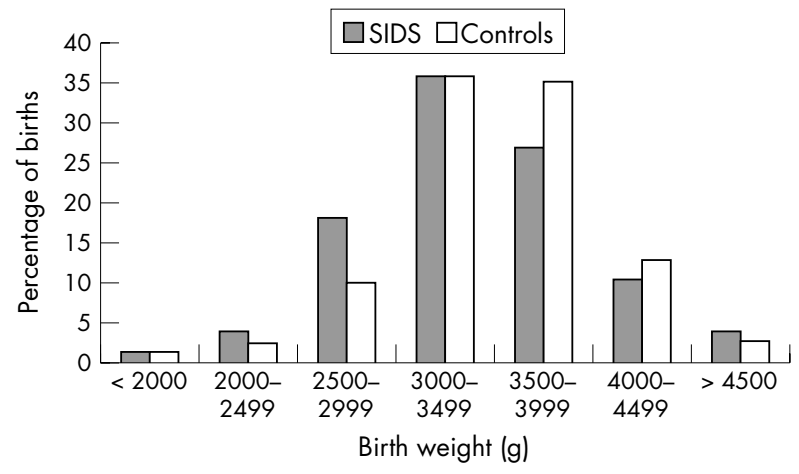

Figure 2 Birth weight distribution in sudden infant death syndrome (SIDS) and controls surviving their first year of life, showing a shift to the left in SIDS compared with controls.

\section{RESULTS}

Compared with controls, cases of SIDS had typical characteristics such as high risk associated with maternal smoking during pregnancy and a decreasing risk with increasing maternal age (tables 1 and 2). Male infants had more than twice the risk of female infants. The risk for SIDS was increased if the infant was not the mother's first child, but previous negative pregnancy outcomes had no effect. Low education (less than 10 years) of the mother was much more common in cases of SIDS than in controls. However, maternal educational level lost its significance in the multiple model because low education was significantly $(p<0.005)$ positively correlated with maternal smoking, low maternal age, and higher parity.

Birth weight and gestational age were not associated with SIDS when included as continuous variables in univariate or multiple models, despite a shift towards lower birth weight in SIDS compared with controls (fig 2). A preterm birth $(<38$ weeks of gestation) was only associated with SIDS in univariate analysis (crude odds ratio $2.4,95 \%$ CI 1.1 to 5.1 ), whereas it was of no significance when corrected for the other variables in the multiple models.
In addition to the established risk factor for SIDS, proteinuria and high fundal height measurements were associated with higher risk. In fact, in almost every second future SIDS victim, the mother had high fundal height measurements, and in a quarter of cases proteinuria was also present. These two variables were not significantly associated with any of the other variables analysed in this study, or with each other.

The risk for SIUD increased with maternal age, high cigarette consumption, maternal overweight or obesity, and low education. There were several significant differences between characteristics of SIDS and SIUD in general. The most striking finding was the opposite tendencies in the risk related to maternal age. There was clearly higher cigarette consumption in pregnancies of later SIDS victims than in those terminating in SIUD. The protective effect of primiparity and female sex of the infants that was seen in the SIDS group differed significantly from the SIUD group. Maternal obesity or overweight, one of the key features of SIUD, was also less likely in SIDS than in SIUD. Whereas differences in the occurrence of proteinuria during pregnancy and abnormally high fundal measurements between the two groups were not significant, abnormally low fundal height measurements were clearly more common in SIUD.

Further, as reported elsewhere, $50 \%$ of SIUD cases were classified as IUGR. High cigarette consumption was the strongest risk factor for SIUD in a IUGR fetus (SIUD ${ }^{\text {IUGR }}$ ) (OR 8.4 (95\% CI 1.8 to 38.7$)$ ), whereas overweight or obesity and maternal age $>35$ years were the two strongest risk factors for SIUD in the normal weight fetus (SIUD ${ }^{\text {not IUGR }}$ ) (OR 19.7 (95\% CI 2.9 to 132.2 ) and OR 12.5 (95\% CI 1.4 to 111.7 ) respectively). Gestational age at time of death was, however, equally distributed in the two groups. SIDS seems to be more comparable to SIUD ${ }^{\mathrm{IUGR}}$, whereas it is significantly different from SIUD ${ }^{\text {not IUGR }}$ in key variables such as maternal age, obesity, smoking habits, and parity, and infant sex (table 2).

\section{DISCUSSION}

In many countries, great progress has been made in the prevention of SIDS through "back to sleep" campaigns. As the prevalence of prone sleeping has decreased significantly, other 
risk factors for SIDS have become more important. The effects of maternal smoking, young age, and high parity have increased..$^{6-8}$ We have also found such effects, and low maternal educational level correlated positively with all of them. Variables not previously reported to be associated with SIDS-that is, high fundal height and proteinuria in pregnancy-may be of future help in the understanding and prevention of SIDS. These findings are too common among controls to have any immediate implications in prevention, but the mechanisms associating these risk factors with SIDS should be studied. In particular, it is interesting that they seem to be unrelated to the established well known risk factors. Why the mothers with subsequent SIDS losses had high fundal measurements is not known, but as it was not related to birth weight, polyhydramnios cannot be ruled out. A common cause of this is maternal diabetes, but there was no association with glucosuria in pregnancy either. It seems unlikely that proteinuria in SIDS would be connected to precursors of pre-eclampsia, as proteinuria in SIDS did not correlate with pregnancy duration or birth weight, as would be expected in pre-eclampsia. In addition, the low maternal age, low proportion of nulliparous women, and heavy smoking associated with SIDS are well known as protective factors against pre-eclampsia.

The mechanisms involved in SIDS are still far from understood. The situation is no better in unexplained antepartum stillbirths, for which validated studies on some risk factors have only recently been published, ${ }^{39}{ }^{10}$ and there has been no decrease in the number of unexplained antepartum stillbirths over the last few decades. Any proof of common causes or mechanisms would be of great value for research and prevention in both fields. Unfortunately, these results do not seem to support this hypothesis, as key epidemiological variables differ significantly between the two groups even in a small sample such as this, the very strong opposite effect of increasing maternal age being the most conspicuous example.

It is commonly accepted that the "triple-risk" model proposed by Rognum and Saugstad ${ }^{11}$ and supported by Filiano and Kinney ${ }^{12}{ }^{13}$ is a useful approach to SIDS research. According to this model, SIDS results from the intersection of three factors: (1) a vulnerable infant; (2) a critical developmental period in homoeostatic control; (3) exogenous stressor(s). This approach may prove useful in SIUD research also.

These conditions obviously have their peak incidence in different critical developmental periods, SIUD at the end of gestation $^{314}$ and SIDS at 2-4 months of age, but both can be affected by the same exogenous stressors in these vulnerable periods. Although the predisposition of the child to sudden unexplained death through maternal and fetal epidemiological characteristics differs in SIDS and SIUD, a possible predisposition from genetic factors cannot be ruled out. The low recurrence rate and low concordance in twin studies indicate that Mendelian inheritance is not involved in most cases of SIDS. ${ }^{15}$ However, it has been reported that some, although few, SIDS victims had a genetic predisposition to cardiac arrhythmias ${ }^{16}$ or defective mitochondrial energy production. ${ }^{17}$ These hypotheses remain to be tested in SIUD.

In terms of exogenous stressors, two interesting candidates are subclinical infections and tobacco constituents, both well documented risk factors for SIDS. ${ }^{18}{ }^{19}$ Irrespective of the infectious agents, the inflammatory process that is elicited is a common finding in SIDS. ${ }^{20}{ }^{21}$ Both systemic endotoxin induced inflammation and nicotine not only prolong laryngeal reflex apnoea and impair respiratory response to hypoxia, ${ }^{22}{ }^{23}$ but also have significant detrimental effects on the perinatal brain during hypoxaemia in the piglet. ${ }^{24}$ Recent studies have shown that bacterial infections and subclinical chorioamnionitis, mainly by Escherichia coli, played an important role in seemingly unexplained antepartum stillbirths. ${ }^{25-27}$ Together, these results may suggest that both nicotine and subclinical infections or fetal inflammatory response reduce perinatal hypoxia tolerance and survival, in both intrauterine life as SIUD and infancy as SIDS.

\section{ACKNOWLEDGEMENTS}

This study was supported by Norwegian Women's Public Health Association and The Norwegian SIDS Society.

\section{Authors' affiliations}

J F Frøen, O D Saugstad, Department of Pediatric Research, The

National Hospital, University of Oslo, Oslo, Norway

J F Frøen, B Stray-Pedersen, Department of Gynecology and

Obstetrics, The National Hospital

M Arnestad, Å Vege, T O Rognum, Department of Forensic Medicine,

The National Hospital

L M Irgens, Medical Birth Registry of Norway, University of Bergen, Bergen, Norway

\section{REFERENCES}

1 Editorial. Unexplained stillbirth. Lancet 1987;i:22-3.

2 Bergman AB, Beckwitt JB, Ray CG. Proceedings of the second international conference on causes of sudden death in infants. Seattle: University of Washington Press, 1970:17-18

3 Frøen JF, Arnestad M, Frey K, et al. Risk factors for sudden intrauterine unexplained death: epidemiologic characteristics of singleton cases in Oslo, Norway, 1986-1995. Am J Obstet Gynecol 2001;184:694-702.

4 Walsh S, Mortimer G. Unexplained stillbirths and sudden infant death syndrome. Med Hypotheses 1995:45:73-5.

5 Irgens LM. The Medical Birth Registry of Norway. Epidemiological research and surveillance throughout 30 years. Acta Obstet Gynecol Scand 2000:79:435-9.

6 Arnestad M, Andersen M, Vege A, et al. Changes in the epidemiological pattern of sudden infant death syndrome in southeast Norway, 1984-1998: implications for future prevention and research Arch Dis Child 2001;85: 108-15.

7 Daltveit AK, Oyen N, Skjaerven R, et al. The epidemic of SIDS in Norway 1967-93: changing effects of risk factors. Arch Dis Child 1997;77:23-7.

8 I'Hoir MP, Engelberts AC, van Well GT, et al. Case-control study of current validity of previously described risk factors for SIDS in The Netherlands. Arch Dis Child 1998;79:386-93.

9 Huang DY, Usher RH, Kramer MS, et al. Determinants of unexplained antepartum fetal deaths. Obstet Gynecol 2000;95:215-21.

10 Maleckiene L, Nadisauskiene R, Bergstrom S. Socio-economic, demographic and obstetric risk factors for late fetal death of unknown etiology in Lithuania: a case-referent study. Acta Obstet Gynecol Scand 2001;80:321-5

11 Rognum TO, Saugstad OD. Biochemical and immunological studies in SIDS victims. Clues to understanding the death mechanism. Acta Paediatr Suppl 1993;82(suppl 389):82-5

12 Kinney HC, Filiano JJ, White WF. Medullary serotonergic network deficiency in the sudden infant death syndrome: review of a 15-year study of a single dataset. J Neuropathol Exp Neurol 2001;60:228-47.

13 Filiano JJ, Kinney HC. A perspective on neuropathologic findings in victims of the sudden infant death syndrome: the triple-risk model. Biol Neonate 1994:65:194-7.

14 Yudkin PL, Wood L, Redman CW. Risk of unexplained stillbirth at different gestational ages. Lancet 1987;1:1192-4.

15 Beal SM. Siblings of sudden infant death syndrome victims. Clin Perinatol 1992;19:839-48

16 Ackerman MJ, Siu BL, Sturner WQ, et al. Postmortem molecular analysis of SCN5A defects in sudden infant death syndrome. JAMA 2001;286:2264-9.

17 Opdal SH, Vege A, Egeland T, et al. Possible role of mtDNA mutations in sudden infant death. Pediatr Neurol 2002; in press.

18 Mitchell EA, Ford RP, Stewart AW, et al. Smoking and the sudden infant death syndrome. Pediatrics 1993:91:893-6.

19 Blackwell CC, Weir DM. The role of infection in sudden infant death syndrome. FEMS Immunol Med Microbiol 1999;25: 1-6.

20 Vege A, Rognum TO. Inflammatory responses in sudden infant death syndrome: past and present views. FEMS Immunol Med Microbiol 1999;25:67-78.

21 Vege A, Rognum TO, Scott H, et al. SIDS cases have increased levels of interleukin-6 in cerebrospinal fluid. Acta Paediatr 1995;84:193-6.

22 Frøen JF, Akre H, Stray-Pedersen B, et al. Adverse effects of nicotine and interleukin-1 beta on autoresuscitation after apnea in piglets: implications for sudden infant death syndrome. Pediatrics 2000; 105:E52.

23 Frøen JF, Akre H, Stray-Pedersen B, et al. Prolonged apneas and hypoxia mediated by nicotine and endotoxin in piglets. Biol Neonate 2002;81:119-25.

24 Frøen JF, Munkeby BH, Stray-Pedersen B, et al. Interleukin-10 reverses acute detrimental effects of endotoxin-induced inflammation on perinatal cerebral hypoxia-ischemia. Brain Res 2002;942:87-94.

25 Maleckiene L, Nadisauskiene R, Stankeviciene I, et al. A case-referen study on fetal bacteremia and late fetal death of unknown etiology in Lithuania. Acta Obstet Gynecol Scand 2000;79: 1069-74.

26 Tolockiene $\mathbf{E}$, Morsing E, Holst $E$, et al. Intrauterine infection may be a major cause of stillbirth in Sweden. Acta Obstet Gynecol Scand 2001;80:511-18

27 Mathews JE, Mathai M, Peedicayil A, et al. Subclinical chorioamnionitis as a causal factor in unexplained stillbirths. Int J Gynaecol Obstet $2001 ; 74: 195-7$ 